\title{
Microcontroller Based Circuit Protection and Control
}

\author{
Usman Ghani, * Chong Hock Siong \\ Centre of Electrical, Power \& Energy Systems,
}

Faculty of Engineering \& the Built Environment, SEGi University

* chonghocksiong@segi.edu.my

\begin{abstract}
The automated microcontroller-based circuit protection and control system is integrated with IoT element, which consisted of both hardware software components, and communication devices. The designed system is to acquire the electrical parameters such as current and voltage as well the power consumption using sensors. ThingSpeak is engaged, mainly used to acquire data from the microcontroller via wireless communication, to further analyse and visualize it in the required form and sends SMS notification to the user through $\mathrm{Wi}-\mathrm{Fi}$, such as over/under current, over/under voltage, \& excessive power consumption, depending on the data analysis. Once user received notification, remedial action can be further taken to isolate faulted part from circuit, or to take desired action for safety purpose. The designed prototype is enhanced circuit protection (automated), incorporating data storage, monitor/control of electrical loads intelligently and offers user safety and security of the electrical operation.
\end{abstract}

\section{Introduction}

Modern electrical equipment continues to increasingly integrated in complexity and real-time monitoring is crucial in industrial, commercial, and residential installations. Simplicity has bring to less components, hence each equipment is considered critical for normal system operations. As such, the importance of circuit protection and overall equipment protection continues to be improved. Determining whether a circuit is adequately protected can require a high-level view of the electrical distribution system, from the fault current available at the source of supply down to the end device connected in 
the system [M. Kezunovic, et al., 2005]. Smart circuit protection system protects circuitry by rapidly disconnecting power to components in the event of fault operation. Even though regulation exists in the form of the various electrical codes, the emergence of wide variety of new \& cheaper product offerings can make the proper selection of circuit protection devices a challenge [Bo, Z. Q., et al., 2013].

Today's manufacturers of electrical and electronic equipment are under constant pressure to speed up production cycle, reduced part count \& size, increase features, improve functionality, enhance reliability and fast response. Products must be small, quick to install, and easy to replace in the field, while saving cost. Circuit protection devices are no exception, and these requirements have been met by the emergence of "smart" devices. The addition of microcontroller has brought-in intelligence, programmability, and communications capabilities to circuit-protection monitoring, control and creating a new class of devices that can protect equipment more effectively [Wang, B., et al., 2011].

Programmable technology using solid-state power control makes it possible to observe and manage the current flow during short circuit, retrieve data, and other information from circuit breakers. It also allows engineers to program relay switching points and response speed to meet the required setting. Many smart relays and circuit breakers include sensing circuits that feed information such as voltage, current flows, back to microcontroller or other control units and can be reset remotely [Bo, Z. Q., et al., 2013].

To appreciate circuit protection and control techniques, it is important to understand the trend of current technologies available. Keeping in mind the broadly-used technologies which employs Arduino-based current and voltage sensors to collect the data flowing through the circuit. Moreover, relay element is used to connect and disconnect the electrical loads from the power source. Furthermore, few communication devices are included in the designed system which helps in interact with the user via Wi-Fi and Bluetooth modules, and 
are being used widely in developed countries [M. Kezunovic and G. Latisko, $2005]$.

\section{Material \& Methods}

This section is all about the design \& elements employed in project to achieve the objectives, which explains in details the hardware and software used to construct the microcontroller-based circuit protection and automated control system to get the desired objectives,

1). To protect the electrical loads from uncertainties occurred in the circuit, detect the faults, and notify the user using microcontroller-based communication interface, for the users to engage immediate remedial action about the situation.

2). To monitor and control the electrical loads, to reduce the power consumption. Figure 1 shows the work flow of the design for protection \& control.

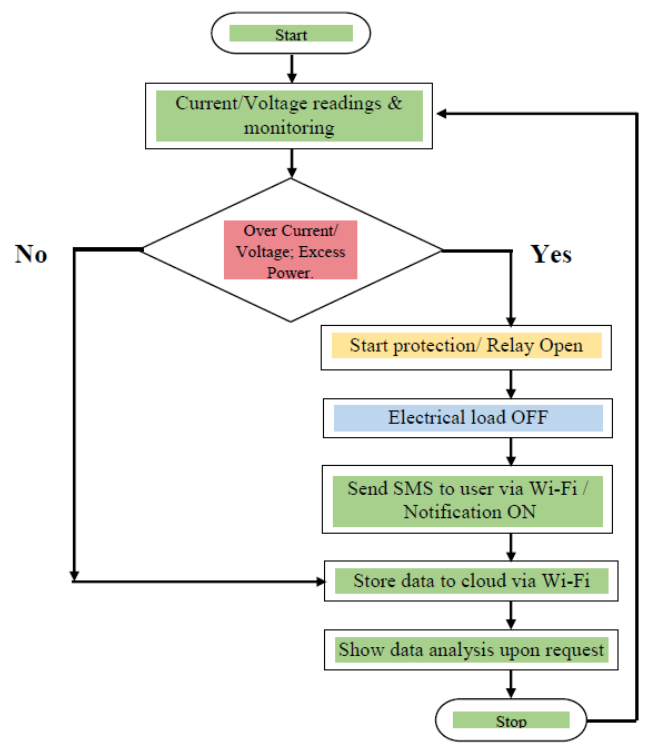

Figure 1. Workflow of microcontroller-based circuit protection and control 


\subsection{The Hardware}

A low cost integrated circuit technology has been widely used all over, for example Arduino has become one of the open source microcontroller platform that can be enhanced its functionality as applied with various types of electronic sensors, electrical devices and communication components due to its simplicity in programming language, ability to transmit digital and analog signals that can be interpreted by computer [Aurilio G., et al., 2014].

Table 1. Project used hardware components' list

\begin{tabular}{|c|c|c|}
\hline No. & Hardware & Main Feature \\
\hline 1 & $\begin{array}{l}\text { Arduino Mega } \\
2560\end{array}$ & $\begin{array}{l}\text { Open-source platform use for controlling electrical and } \\
\text { electronic devices using source code }\end{array}$ \\
\hline 2 & $\begin{array}{l}\text { AC/DC voltage } \\
\text { sensor }\end{array}$ & Designed for $\mathrm{AC}$ and DC voltage measurement in a wire. \\
\hline 3 & Wi-Fi module & $\begin{array}{l}\text { Used for communication purpose, upload sensor's data to } \\
\text { cloud, and sending notifications to user about circuit } \\
\text { situation. }\end{array}$ \\
\hline 4 & $\begin{array}{l}\text { Bluetooth } \\
\text { module }\end{array}$ & $\begin{array}{l}\text { Designed for making wireless serial communication } \\
\text { between two microcontrollers. }\end{array}$ \\
\hline 5 & $\begin{array}{l}\mathrm{AC} / \mathrm{DC} \text { current } \\
\text { sensor }\end{array}$ & Designed for AC and DC current measurement in a wire. \\
\hline 6 & LCD & $\begin{array}{l}\text { Flat panel display to see the output results in digital form } \\
\text { on screen mainly to see the input from keypad. }\end{array}$ \\
\hline 7 & LEDs & Used as an indicator with light. \\
\hline 8 & Buzzer & Used as an indicator with sound. \\
\hline 9 & Matrix keypad & Set of buttons for user input and functionality. \\
\hline 10 & Resistor & Used to reduce current flow, adjust signal levels. \\
\hline 11 & $\begin{array}{l}\text { DC power } \\
\text { adapter }\end{array}$ & For steady power supply, regulated voltage. \\
\hline 12 & Jumper Wires & Used to interconnect electrical \& electronic components. \\
\hline 13 & Breadboard & $\begin{array}{l}\text { A solder less device used for interconnect electrical } \\
\text { components using jumper wires. }\end{array}$ \\
\hline 14 & PC/Laptop & Used for writing code and data transferring. \\
\hline 15 & 2-Ch Relay & Work as a switch, used for controlling electrical load \\
\hline 16 & USB Cable & Used to transfer data/ program from laptop to Arduino. \\
\hline
\end{tabular}




\subsubsection{Arduino Mega 2560 Microcontroller}

Arduino is an open-source electronics platform based on AT Mega microcontroller. It comes in different models to cater to different needs. The commonly used ones are Arduino Uno and Arduino Mega. Arduino IDE is used for programming an Arduino. A microcontroller is a small computer on a single integrated circuit containing a processor core, memory, and programmable input/output peripherals [Alsibai M.H., Siang H.M., 2015]. The peripherals of microcontroller are given below;

- Analog \& Digital I/O: Provides the ability to control and read input \& output.

- A/D Conversion: To convert analog to digital form, to be processed.

- D/A Conversion: To convert digital to analog form, to be processed.

- Serial Interface: The serial interface is used to transfer data between devices within a system and between systems.

- Timers: Ability to control duration of event.

- Flash Memory Used to store program code and data.

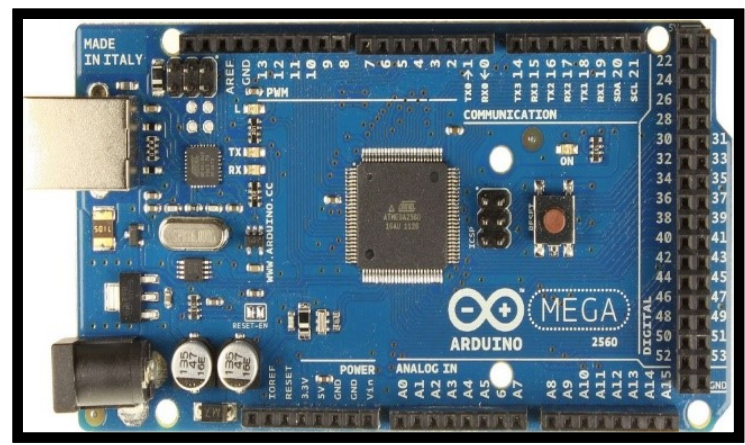

Figure 2. Arduino Mega 2560 microcontroller

\subsubsection{ESP 8266 Wi-Fi Module}

ESP $8266 \mathrm{Wi}-\mathrm{Fi}$ module is a chip that provides access to a network for microcontroller via Wi-Fi. ESP 8266 is having TCP/IP communication protocol integrated on chip. This piece is operating with $3.3 \mathrm{~V}$ which make it hard to directly interconnect with Arduino UNO. So, supply voltage needs to be reduced from $5 \mathrm{~V}$ to $3.3 \mathrm{~V}$ to power the communication. Hence, the 
communication between ESP 8266 and Arduino UNO is done through UART interface because ESP 8266 is a programmed system on chip. This module can communicate with Arduino UNO through hardware pins (RX and TX). ESP 8266 has an ability to be programmed in order to access a network. Arduino UNO sends the AT commands to enable the ESP 8266 to connect to local network. This Wi-Fi module can be used in either way as client mode or as server mode, where microcontroller will have the ability to access any website or cloud to upload data of the sensors [Gill S.P.S., 2012].

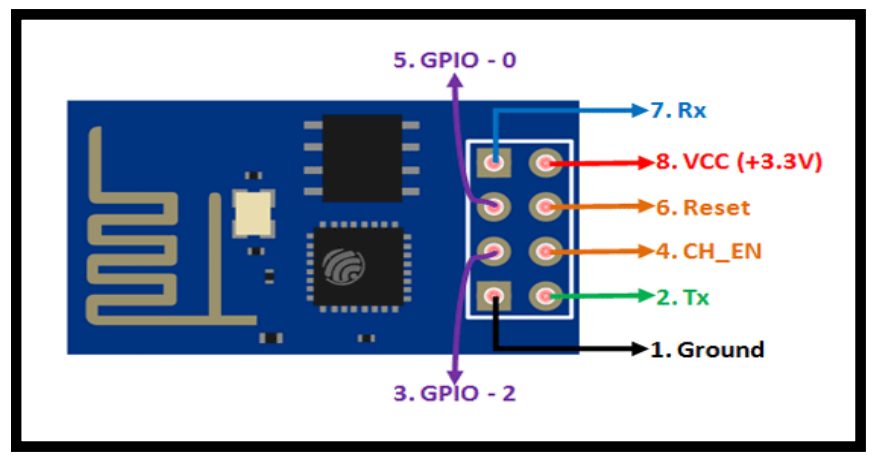

Figure 3. ESP $8266 \mathrm{Wi-Fi}$ module

\subsubsection{HC-06 Bluetooth Module}

HC-06 module is Bluetooth SPP (serial port protocol) module, designed for transparent wireless serial connection setup. The HC-06 Bluetooth module can be used in a Master or Slave configuration, making it a great solution for wireless communication. The role of the module (master or slave) can be configured only by AT commands. The slave modules cannot initiate a connection to another Bluetooth device, but can accept instruction. Master module can initiate a connection to other devices. This serial port Bluetooth module is fully qualified Bluetooth V2.0 EDR (enhanced data rate) 3Mbps modulation with complete $2.4 \mathrm{GHz}$ radio transceiver and baseband. It uses CSR External single chip Bluetooth system with CMOS technology and with AFH (Adaptive Frequency Hopping feature) [Gill S.P.S., 2012]. 


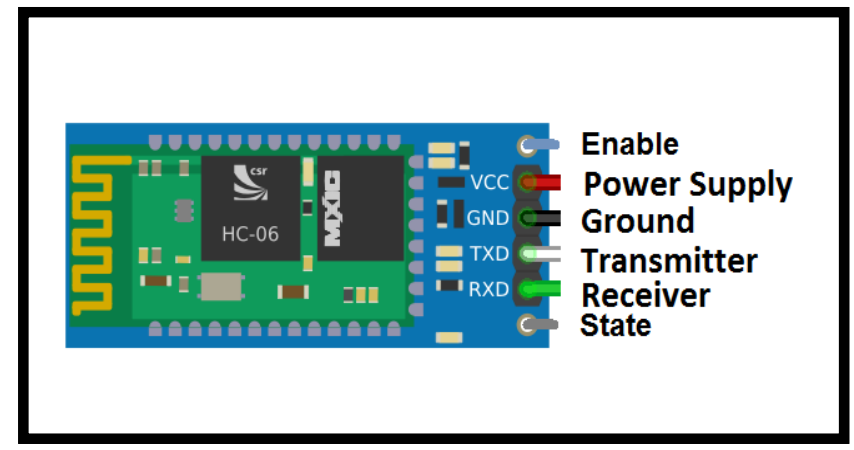

Figure 4. HC-06 Bluetooth module

\subsubsection{2-Channel 5V Relay Module}

2-Channel relay module consists of 2 relays placed in parallel and share same Vec and ground with different input signals. A relay is a coil switch that can be triggered with $5 \mathrm{~V}$ to shift the contactor in order to open and close, controlling secondary higher voltage circuit of 250VAC /30VDC. The figure shown below is a 5V 2-Channel relay interface board, and each channel needs a $15-20 \mathrm{~mA}$ driver current. It can be used to control various appliances and equipment with large current. It is equipped with high-current relays that work under $\mathrm{AC} 250 \mathrm{~V} 10 \mathrm{~A}$ or $\mathrm{DC} 30 \mathrm{~V} 10 \mathrm{~A}$. It has a standard interface that can be controlled directly by microcontroller. The module is supplied with power via the pin labeled Vcc and ground via the pin labeled GND. The relays are energized with low inputs to the IN1 and IN2 inputs. There are four relays that each provide dry contact outputs. That is to say that each relay provides a common (COM), normally open (NO) and a normally closed (NC) terminal [Alsibai M.H., Siang H.M., 2015]. 


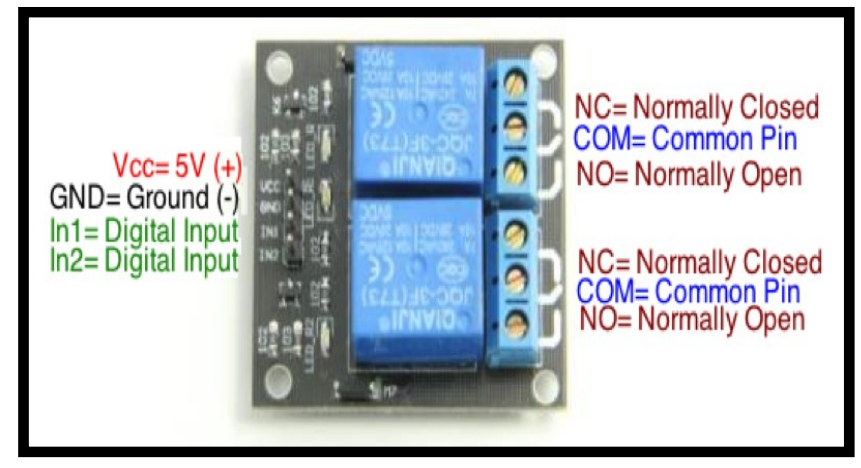

Figure 5. 2-Channels 5V relay module

\subsubsection{ACS 712 Current Sensor Module}

The ACS712 is a current sensing device which offers an economical and precision in sensing AC and DC currents based on the principle of Hall-effect. It consists of a precise, low-offset, linear Hall sensor circuit with a copper conduction path located near the surface of the die. When current is applied through the copper conductor, a magnetic field is generated which is sensed by the built-in Hall element. The strength of the magnetic field is proportional to the magnitude of the current through the conduction path, providing a linear relationship between the output Hall voltage and input conduction current. The on-chip signal conditioner and filter circuit stabilize and enhances the induced Hall voltage to an appropriate level so that it could be measured through an ADC channel of a microcontroller. The ACS712 device eliminates the risk of damaging the current monitoring circuit due to the high voltage on the conduction side. The electrical isolation between the conduction current and the sensor circuit through relay also minimizes the safety concerns while dealing with high voltage systems [Aurilio G., et al., 2014]. 


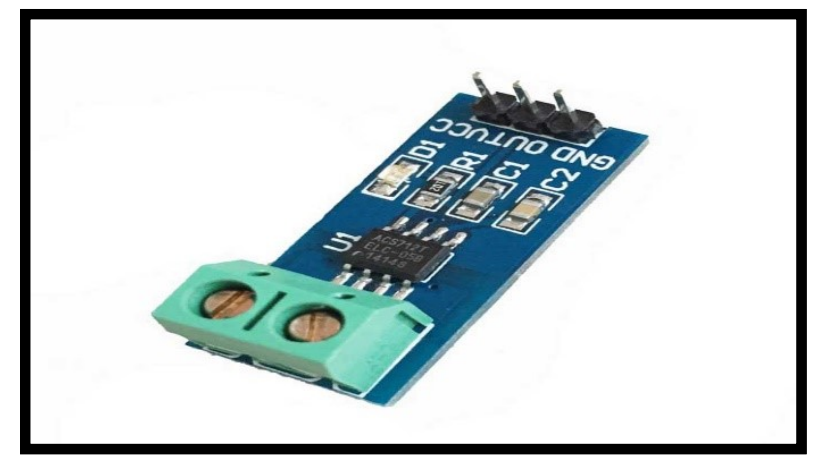

Figure 6. ACS 712 current sensor module

\subsubsection{V-DC Voltage Sensor Module}

This module is based on resistance principle, where the input voltage of red terminal is reduced 5 times of original voltage. The maximum Arduino analog input voltage is $5 \mathrm{~V}$, so the input voltage of this module should be not more than $5 \mathrm{~V}$ x $5=25 \mathrm{~V}$ (for $3.3 \mathrm{~V}$ system, the input voltage should be not more than $3.3 \mathrm{~V}$ x $5=16.5 \mathrm{~V}$ ). Since the Arduino chip have 10-bit AD, hence module simulation resolution is $0.00489 \mathrm{~V}(5 \mathrm{~V} / 1023)$, and the input voltage of this module should be more than $0.00489 \mathrm{~V}$ x $5=0.02445 \mathrm{~V}$ [Aurilio G., et al., 2014].

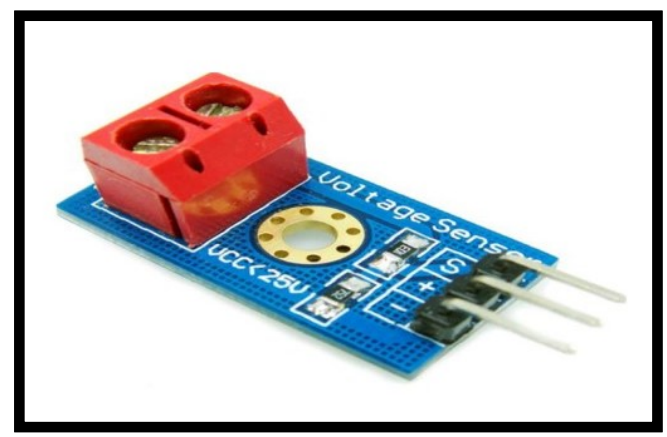

Figure 7. 25V DC voltage sensor module 


\subsubsection{The Software}

Software is the most important thing in prototype of control system in order to programme to get desired output. There are several software used in this project such as Arduino 1.6.12, where C programming language is the core of programming for microcontroller unit (Arduino UNO). Also, this project needs other software to acquire and store data in cloud via communication, as well data analysis, for example ThingSpeak [Tamkittikhun N., Tantidham T., Intakot P., 2015].

\subsubsection{Arduino 1.6.12}

A program for Arduino hardware may be written in any programming language with compilers that produce binary machine code for the targeted processor. The Arduino integrated development environment (IDE) is a crossplatform application that is written in the programming language Java. It originated from the IDE for the languages Processing and Wiring. It includes a code editor with features such as text cutting and pasting, searching and replacing text, automatic indenting, brace matching, and syntax highlighting, and provides simple one-click mechanisms to compile and upload programs to an Arduino board. The Arduino IDE supports the languages $\underline{\mathrm{C}}$ and $\underline{\mathrm{C}++}$ using special rules of code structuring. The Arduino IDE employs the program to convert the executable code into a text file in hexadecimal encoding that is loaded into the Arduino board by a loader program in the board's firmware [Tamkittikhun N., Tantidham T., Intakot P., $2015]$.

\subsubsection{ThingSpeak}

ThingSpeak is an open source Internet of Things (IoT) application and is used to store and retrieve sensor data from Arduino using the HTTP protocol over the Internet or via a Local Area Network. ThingSpeak application enables the capture of sensor logging info, as well the location tracking applications. ThingSpeak integrated support from the numerical computing software MATLAB from MathWorks, allowing ThingSpeak users to 30 nalyse and visualize uploaded data without requiring the purchase of 
license, mainly for monitoring \& dispensing information [Tamkittikhun N., Tantidham T., Intakot P., 2015].

\section{Key Features and Applications}

The designed microcontroller-based circuit protection and control ideally designed for use at small industries and household areas. The system is based on easily available, user friendly hardware component and protection devices, simple used software and smartphone application and most importantly Arduino Mega 2560 microcontroller which integrated to communicate hardware and software components to each other.

\subsection{Automatic Circuit Protection System}

The combination of current sensor, voltage sensor, and relay modules are connected to the Arduino microcontroller in between power source and electrical loads. The current sensor and voltage sensor read the current and voltage flowing through the circuit and sends the data to the microcontroller. The programmable relay module can be controlled by writing code to the Arduino and each relay channel assigned the preset voltage and current value to switch ON and OFF accordingly, cutting the circuit connection. Hence, whenever the current and voltage flow increase or decrease than the preset values the relay starts operating.

\subsection{Cloud Data Storage Circuit Monitoring System}

ThingSpeak provides online server where the sensors' data can be uploaded and store. The current and voltage reading observed in the circuit protection are further uploaded to the ThingSpeak channel, and be able to convert data into graphical form which is suitable for monitoring purpose. The ThingSpeak server further connects to the Android Virtuino App by using API keys generated by the ThingSpeak channel and it helps to visualize sensors data to the end user and such application also offers to send SMS notification to the user and authorized personnel about the circuit condition.

\section{Results and Discussion}


This section of the report is more towards the outcomes of the prototype and there is a discussion on the results of microcontroller-based circuit protection and control system. Moreover, it strives to prove whether the purposes are favorably settled or not. The values taken from the current sensor and voltage sensor appeared in serial monitor following varying circumstances. Furthermore, the consequences of ThingSpeak will be cultivated and presented with altered graphs and schemes to heighten the reliability and communication of the protection and control system. The graphs will help in providing a profound power monitoring system's data using Wi-Fi role. The notification about the circuit situation will be manifested and examined when the regularity has multi positions and announcements. Therefore, the events will be posted according to the measures of methodology.

\subsection{Case Study of Current \& Voltage Sensors Measurements Under Different Conditions}

\subsubsection{Condition 1: Over/Under Voltage Condition}

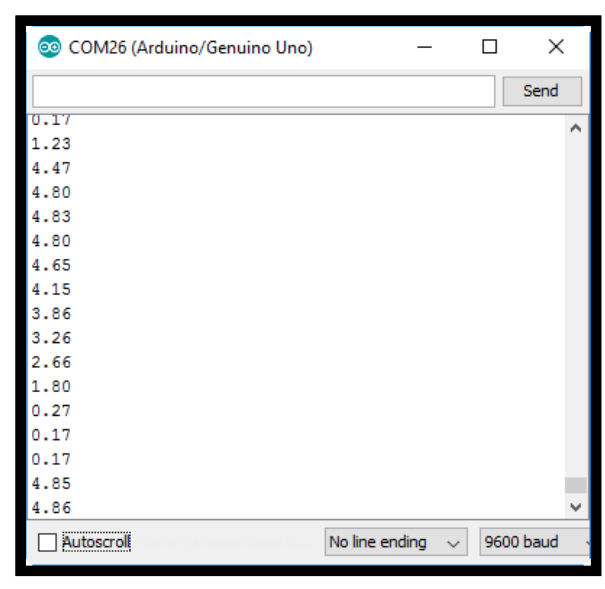

Figure 8. Serial monitor readings from $25 \mathrm{~V}$ DC voltage sensor module

The above Figure 8 shows the serial monitor reading sensed by voltage sensor module using Arduino Mega microcontroller. The voltage varies from $0-25 \mathrm{~V}$, but stated figure shows the range from $0-5 \mathrm{~V}$ as the power supplied by $5 \mathrm{~V}$ DC adapter, but voltage can be changed by using voltage regulator. From the serial monitor, the preset values can be assigned to relay for over / under 
voltage condition. The below Table 2 classify the $25 \mathrm{~V}$ DC voltage sensor module readings.

Table 2. Condition classification of $25 \mathrm{~V}$ DC voltage readings using IF function

\begin{tabular}{|l|l|l|l|}
\hline Conditions & $\begin{array}{l}\text { Measurement } \\
\text { range } \\
\text { (Volts) }\end{array}$ & $\begin{array}{l}\text { IF function } \\
\text { coding }\end{array}$ & $\begin{array}{l}\text { Relay } \\
\text { switch } \\
\text { status }\end{array}$ \\
\hline Under voltage & $0-3.99$ & $\begin{array}{l}\text { if (voltage1 } \\
<=3.99)\end{array}$ & ON \\
\hline $\begin{array}{l}\text { Operating } \\
\text { voltage }\end{array}$ & $4.0-9.99$ & $\begin{array}{l}\text { else if(voltage1 } \\
<=9.99)\end{array}$ & OFF \\
\hline Over voltage & $10.0-25.0$ & $\begin{array}{l}\text { else if(voltage1 } \\
<=25.0)\end{array}$ & ON \\
\hline
\end{tabular}

\subsubsection{Condition 2: Over/ Under Current Condition}

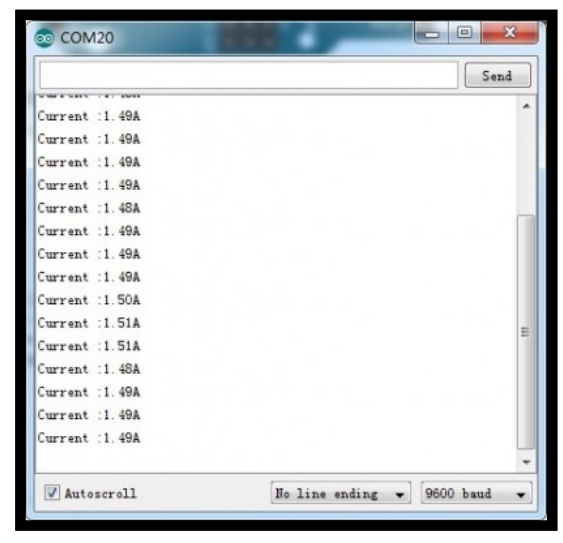

Figure 9. Serial monitor readings from ACS 712 current sensor

Figure 9 shows the serial monitor reading sensed by ACS 712 current sensor using Arduino Mega microcontroller. The current varies from 0-4A, but stated figure shows the range from $0-1.5 \mathrm{~A}$ because of DC power supplied through $5 \mathrm{~V}$ and $1.5 \mathrm{~A}$. From the serial monitor, the preset values can be assigned to relay for over current and under current condition. Table 3 classify the ACS 712 current sensor readings condition. 
Table 3. Condition classification of ACS 712 current reading using IF function

\begin{tabular}{|l|l|l|l|}
\hline Conditions & $\begin{array}{l}\text { Measurement } \\
\text { range (Amp) }\end{array}$ & $\begin{array}{l}\text { IF function } \\
\text { coding }\end{array}$ & $\begin{array}{l}\text { Relay } \\
\text { switch } \\
\text { status }\end{array}$ \\
\hline Under current & $0-0.99$ & $\begin{array}{l}\text { if (current1 } \\
<=0.99)\end{array}$ & ON \\
\hline Operating current & $1.0-1.99$ & $\begin{array}{l}\text { else if (current1 } \\
<=1.99)\end{array}$ & OFF \\
\hline Over current & $2.0-4.0$ & $\begin{array}{l}\text { else if (current1 } \\
<=4.0)\end{array}$ & ON \\
\hline
\end{tabular}

\subsubsection{Condition 3: Excessive Power Consumption Condition}

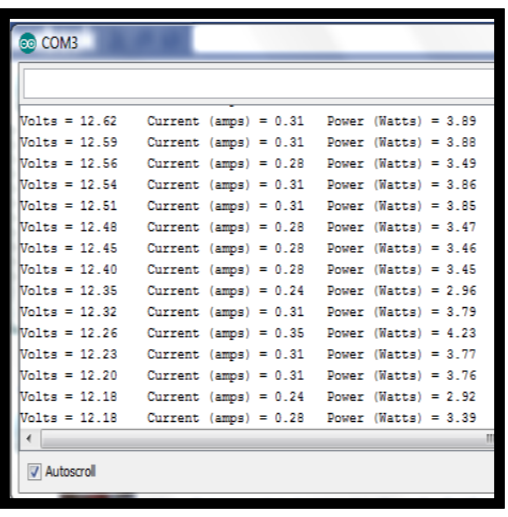

Figure 10. Serial monitor readings for power consumption

Figure 10 shows the serial monitor reading calculated by applying power consumption formula which is $\mathrm{P}=\mathrm{V}^{*} \mathrm{I}$ (power is the product of voltage and current). It is calculated by using the observed current and voltage value. From the serial monitor, the preset values can be assigned to relay for normal power consumption and excessive power consumption. Table 4 below classify the power consumption condition, where $\mathrm{I}_{\max }$ is $2.0 \mathrm{~A}$, and $\mathrm{V}_{\max }$ is $10 \mathrm{~V}$. 
Table 4. Classification of power consumption readings using IF function

\begin{tabular}{|l|l|l|l|}
\hline Conditions & $\begin{array}{l}\text { Power } \\
\text { consumption } \\
\text { range Power (W) }\end{array}$ & $\begin{array}{l}\text { IF function } \\
\text { coding }\end{array}$ & $\begin{array}{l}\text { Relay } \\
\text { switch } \\
\text { status }\end{array}$ \\
\hline $\begin{array}{l}\text { Normal power } \\
\text { consumption }\end{array}$ & $0-20 \mathrm{~W}$ & if (power $<=20)$ & OFF \\
\hline $\begin{array}{l}\text { Excessive } \\
\text { power } \\
\text { consumption }\end{array}$ & $21-48$ & $\begin{array}{l}\text { else if (power } \\
<=48)\end{array}$ & ON \\
\hline
\end{tabular}

\subsection{Thingspeak Channel Outputs}

The ESP 8266 Wi-Fi module is integrated with the microcontroller-based circuit control and protection system. Connectivity access through coding, it has the ability to send data from current sensor and voltage sensor to the virtual server, via ThingSpeak channel. The Wi-Fi module will encode/ decode of the collected data, with coding functionality look into the readings of each sensor. The results of all collected data are plotted under different categories and graphs are updated in every 15 seconds, shown in the following figures.

\subsubsection{Over / Under Current Monitoring}

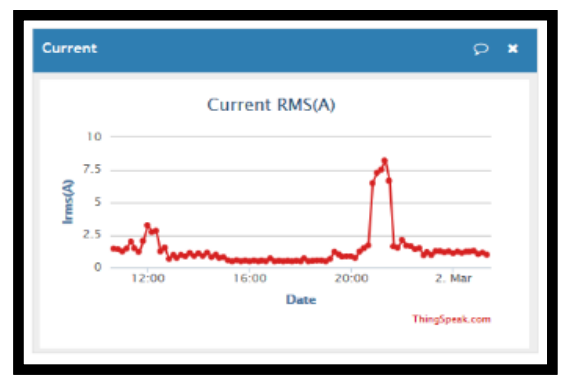

Figure 11. ThingSpeak channel RMS current output [i.e. Over current Relay ON (4.51 - 10A); Relay OFF (2.1 - 4.5A); Under current Relay ON (0 2A)] 


\subsubsection{Over / Under Voltage Monitoring}

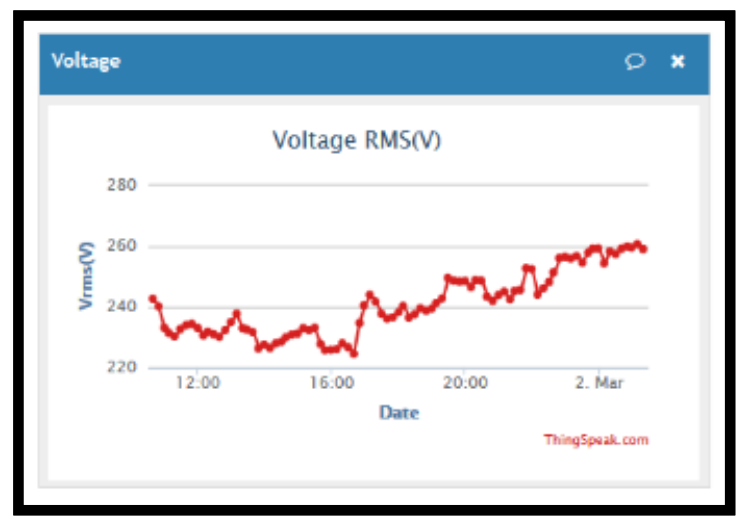

Figure 12. ThingSpeak channel RMS voltage output [i.e. Over voltage Relay ON (256 - 280V); Relay OFF (236 - 255V); Under voltage Relay ON $(220-235 \mathrm{~V})]$

\subsubsection{Excessive Power Consumption Monitoring}

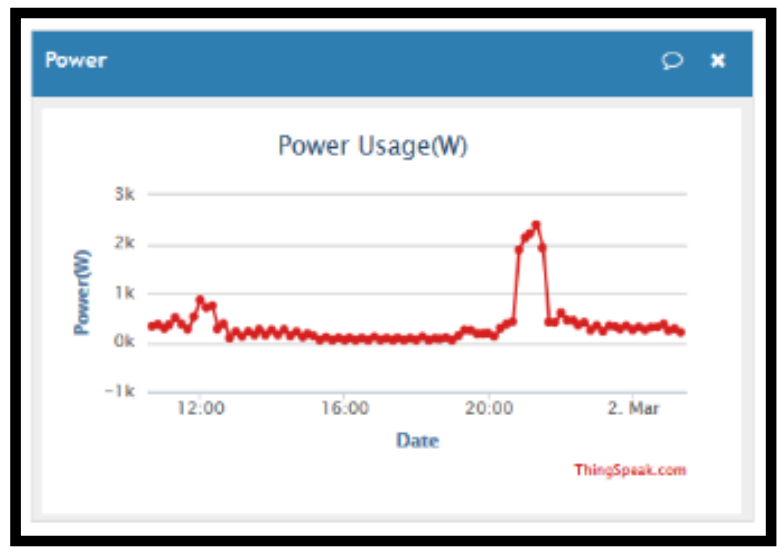

Figure 13. ThingSpeak channel Power consumption output [i.e. Normal consumption Relay OFF (0-20W); Excessive consumption Relay ON (20$30 \mathrm{~W})$ ] 


\subsubsection{SMS Notifications Using Thingspeak and Virtuino App}

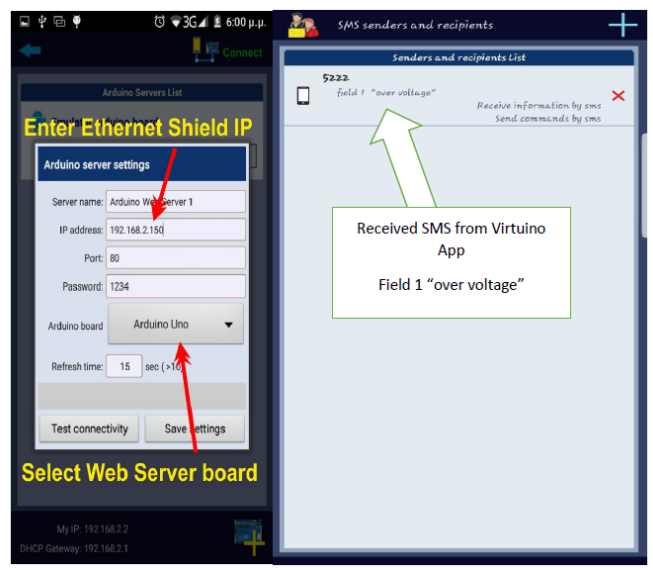

Figure 14. Connecting to Server and SMS notification using Virtuino App

The ThingSpeak server communicates with Virtuino App using IP address. Data import done using API write and API read keys. While creating ThingSpeak channel, the website generates channel ID and API keys specifically which can be further use for communicating with other web servers. Virtuino App also use API keys to check the channel readings of ThingSpeak channel and generate SMS to send to the end user. The Table 4.7 shows that how ThingSpeak channel ID and API keys received from ThingSpeak website and put in to the Virtuino App. Figure 14 shows the communication setting between Virtuino App and Arduino microcontroller. It also shows the SMS received from Virtuino App to the user about over voltage detected in circuit. 
Table 5. Classification of readings from ThingSpeak channel for SMS notification

\begin{tabular}{|c|c|c|c|}
\hline \multicolumn{4}{|c|}{ Condition 1: Current flow reading } \\
\hline Conditions & $\begin{array}{l}\text { RMS current } \\
\text { reading }\left(\mathrm{I}_{\text {rms }}\right)\end{array}$ & $\begin{array}{l}\text { IF function } \\
\text { coding }\end{array}$ & $\begin{array}{l}\text { Send SMS } \\
\text { Notification }\end{array}$ \\
\hline Under current & $0-2.0$ & if (current $<=2.0$ ) & YES \\
\hline $\begin{array}{l}\text { Operating } \\
\text { current }\end{array}$ & $2.10-4.50$ & $\begin{array}{l}\begin{array}{l}\text { else if (current } \\
<=4.50)\end{array}\end{array}$ & $\mathrm{NO}$ \\
\hline Over current & $4.51-10.0$ & $\begin{array}{l}\text { else if (current } \\
<=10.0 \text { ) }\end{array}$ & YES \\
\hline \multicolumn{4}{|c|}{ Condition 2: Voltage flow reading } \\
\hline Conditions & $\begin{array}{l}\text { RMS voltage } \\
\text { reading }\left(V_{\text {rms }}\right)\end{array}$ & $\begin{array}{l}\text { IF function } \\
\text { coding }\end{array}$ & $\begin{array}{l}\text { Send SMS } \\
\text { Notification }\end{array}$ \\
\hline Under voltage & $220-235$ & $\begin{array}{l}\text { if } \\
<=235)\end{array}$ & YES \\
\hline $\begin{array}{l}\text { Operating } \\
\text { voltage }\end{array}$ & $236-255$ & $\begin{array}{l}\text { else if (voltage } \\
<=255)\end{array}$ & $\mathrm{NO}$ \\
\hline Over voltage & $256-280$ & $\begin{array}{l}\text { else if (voltage } \\
<=280)\end{array}$ & YES \\
\hline \multicolumn{4}{|c|}{ Condition 3: Power consumption reading } \\
\hline Conditions & $\begin{array}{l}\text { Power } \\
\text { consumption } \\
\text { reading }(\mathbf{W})\end{array}$ & $\begin{array}{l}\text { IF function } \\
\text { coding }\end{array}$ & $\begin{array}{l}\text { Send SMS } \\
\text { Notification }\end{array}$ \\
\hline $\begin{array}{l}\text { Normal power } \\
\text { consumption }\end{array}$ & $0-20$ & if (power $<=20$ ) & NO \\
\hline $\begin{array}{l}\text { Excessive } \\
\text { power } \\
\text { consumption }\end{array}$ & $20-30$ & $\begin{array}{l}\text { else if (power } \\
<=30)\end{array}$ & YES \\
\hline
\end{tabular}

\section{Conclusion}

The microcontroller-based circuit protection and control system used in this project is an IoT based structure consist of hardware, software components, and communication devices. The designed system has the ability to acquire the electrical parameters such as current / voltage values and provide platform of monitoring, for example, under / over or excessive / normal power consumption. The system is designed to control power through relay on/ off, the setting in accordance to the needs. Also able to store captured data in the cloud and to visualize data in graphical form through ThingSpeak channel (updated in every certain period). Collected data was analyse in such 
way that the setting was assigned (over/ under voltage or current) to allow the turn $\mathrm{ON} / \mathrm{OFF}$ output relay to protect the circuit from harm. Also, once excessive power consumption is detected by the system, an SMS notification will be sent for user to take desired action. ThingSpeak server is connected to the Virtuino App to relay notification through SMS. The designed prototype is apply to alert user about the happening in power consumption, enable to capture \& store data to the cloud, observe collective info \& present to user summary in graphical form to allow user to control electrical consumption effectively, as well offering the user safety \& electrical protection.

\section{References}

Alsibai M.H., Siang H.M., 2015, A smart driver monitoring system using android application and embedded system; Proceedings of the 5th IEEE International Conference on Control Systems, Computing and Engineering (ICCSCE 2015); Penang, Malaysia; pp. 242-247.

Aurilio G., Gallo D., Landi C., Luiso M., Cigolotti V., Graditi G., 2014, Low cost combined voltage and current transducer for Smart Meters; Proceedings of the 2014 IEEE International Instrumentation and Measurement Technology Conference; Montevideo, Uruguay; pp. 1459-1464.

Bo, Z. Q., Weller, G., \& Lomas, T., 2000, Positional protection of transmission system using global positioning system. IEEE Transactions on Power Delivery, 15(4), pp. 1163-1168.

Bo, Z. Q., Zhang, B. H., Dong, X. Z., He, J. H., et al., 2013, The development of protection interlocution and smart relay network, Power System Protection and Control, 41(2), pp. 1-12.

Gill S.P.S., 2012, Smart Power Monitoring Utility System Using Wireless Sensor Networks; Proceedings of the 2012 Sixth International Conference on Sensing Technology; Kolkata, India; pp. 5-114.

M. Kezunovic and G. Latisko, 2005, Automated monitoring functions for improved power system operation and control," presented at the IEEE PES Summer Meeting, San Francisco, USA. 
M. Kezunovic, T. Djokic, and T. Kostic, 2005, Robust topology determination based on additional substation data from IEDs, PowerTech 05, St. Petersburg, Russia.

M. Kezunovic, Z. Ren, G. Latisko, D. R. Sevcik, J. Lucey, W. Cook, E. Koch, 2005, Automated Monitoring and Analysis of Circuit Breaker Operation, IEEE Transactions on Power Delivery, Vol. 20, No. 3, pp. 1910-1918.

M. Kezunovic and G. Latisko, 2005, Automated monitoring functions for improved power system operation and control, IEEE, San Francisco, USA.

Tamkittikhun N., Tantidham T., Intakot P., 2015, AC power meter design based on Arduino: Multichannel single-phase approach; Proceedings of the 19th International Computer Science and Engineering Conference (ICSEC): Hybrid Cloud Computing: A New Approach for Big Data Era; Chiang Mai, Thailand.

Wai Mar Myint Aung, Yadanar Win, Nay Win Zaw, 2018, Implementation of Solar Photovoltaic Data Monitoring System, International Journal of Science, Engineering and Technology Research, Vol. 7, Issue 8, ISSN: 2278 -7798.

Wang, B., Dong, X. Z., Xu, F., Cao, R. B., Liu, K., \& Bo, Z. Q., 2011, Analysis of data sharing for protection and control system in smart distribution substation, Proceedings of the CSEE, Vol. 31. 